\title{
Prevalence and associated factors for stunting, underweight and wasting among children under 6 years of age in rural Hunan Province, China: a community-based cross-sectional study
}

Huixia Li

Hunan Provincial Maternal and Child Health Care Hospital

Shan Yuan

Hunan Provincial Maternal and Child Health Care Hospital

Hualing Fang

Hunan Provincial Maternal and Child Health Care Hospital

Guangwen Huang ( $\nabla 413603 a @ 163 . c o m$ )

Hunan Provincial Maternal and Child Health Care Hospital

\section{Qun Huang}

Hunan Provincial Maternal and Child Health Care Hospital

\section{Hua Wang}

Hunan Provincial Maternal and Child Health Care Hospital

\section{Aihua Wang}

Hunan Provincial Maternal and Child Health Care Hospital

\section{Research Article}

Keywords: Children, stunting, underweight, wasting, prevalence, rural, China

Posted Date: February 23rd, 2021

DOI: https://doi.org/10.21203/rs.3.rs-200393/v1

License: (c) (1) This work is licensed under a Creative Commons Attribution 4.0 International License.

Read Full License

Version of Record: A version of this preprint was published at BMC Public Health on March 11th, 2022. See the published version at https://doi.org/10.1186/s12889-022-12875-w. 


\section{Abstract \\ Background}

The existing epidemiological data cannot represent the situation of malnutrition among Chinese children, particularly those in rural China. Hence, in this community-based cross-sectional study, the prevalence and associated factors of stunting, underweight and wasting among children (age $<6$ years) from rural Hunan Province were analyzed.

\section{Methods}

Totally 5529 children aged 0 to 71 months and their caregivers were randomly chosen by multistage stratified cluster sampling from 72 villages from rural Hunan, which covered 24 towns in 12 counties. Data about the children and their mothers, caregivers and family conditions was acquired using unified questionnaire, and the length/height and weight of each child were measured using unified instruments. The prevalence of malnutrition among children were evaluated using the length/height for age, weight for age, weight for length/height, and body mass index for age $z$ scores, which were computed according to the 2006 and 2007 WHO Child Growth Standards.

\section{Results}

The prevalence of stunting, underweight, and wasting among the 5529 children are $4.4 \%$ (241), 3.9\% (217), and 4.0\% (221), respectively. The significant associated factors on higher risks of malnutrition in the children are low birth weight, maternal gestational weight gain $<10 \mathrm{~kg}$ (stunting); low birth weight, maternal gestational weight gain $<10 \mathrm{~kg}$, ethnicity of caregivers being minority (underweight); low birth weight, ethnicity of caregivers being minority (wasting). High education level of caregivers and high family food expenditure are common protective factors for all three types of malnutrition, except that high family food expenditure is not protective for wasting.

\section{Conclusions}

The prevalence of stunting, underweight and wasting is low among rural children under age of 6 years in Hunan. As for the measures, the gestational care and reasonable diet of mothers should be strengthened, and nutritional deficiency during pregnancy be avoided, which will prevent low birth weight. Education about nutrition must be promoted among minorities.

\section{Background}

The malnutrition of children includes protein-energy malnutrition and micronutrient deficiency. The former consists of three indices of stunting, underweight and wasting. In particular, stunting and wasting reflect 
the chronic or acute malnutrition of children, and underweight reveals the current malnutrition status, but cannot differentiate near-term or long-term malnutrition[1]. Malnutrition of different forms may coexist in children. Preschool children are at the key stage of growth and development, and malnutrition occurring at this stage may cause irreversible near-term and long-term effects on the health of children. Such effects include delayed physical and cognitional development[2-4], even increases the risks of infection and death, and also increases the risks of hypertension, diabetes and other chronic diseases at adulthood[5].

About 0.149 billion children under 5 years of age suffered stunting and about 49 million children had wasting in 2018 according to data from United Nations International Children's Emergency Fund (UNICEF) and Worth Health Organization (WHO)[6]. Malnutrition of children is a major public health problem in developing countries, especially Africa and Southeast Asia. Reportedly, the prevalence of stunting, underweight, and wasting among children under 5 years of age in low- and middle-income countries are $29.0 \%, 15.5 \%$ and $7.5 \%$, respectively [7]. Malnutrition of children can be caused by many factors. A large number of observational studies have shown that poor socioeconomic condition, unreasonable addition of supplementary food, household food insecurity, diseases of children (e.g. recurrent respiratory infections and diarrhea), inadequate maternal nutritional status, and low education level of caregivers are all associated with the malnutrition of children[8-13].

China is a developing country in East Asia. In the past 30 years, with the rapid socioeconomic development, the food supply is increasingly abundant, and the nutrition status of children has been significantly improved. Nevertheless, malnutrition still commonly occurs in poor rural areas of China. Nationwide nutrition surveys in China show that the prevalence of stunting and underweight among children under 5 years of age between 1990 and 2010 dropped from $33.1-9.9 \%$ and from $13.7-3.6 \%$ respectively, but were still up to $20.3 \%$ and $8.0 \%$ respectively in rural China[5, 8]. To further improve the nutrition status of children in poor rural areas, National Health Committee of China extensively implemented children nutrition improvement projects in poor rural areas since 2012, including food supplements and nutrition education[14]. So far, children nutrition improvement projects have been implemented for eight years throughout China. The epidemiological investigations in 2010 cannot reflect the current malnutrition levels of children in rural China. Though some children malnutrition investigations have been conducted in rural China recently, the investigated age ranges are narrow and concentrated on under 3 years[15-17]. In particular, relevant research on preschool children is insufficient[18].

In the new era, systematic study on the malnutrition of children under 6 years of age in rural areas and discovery of key associated factors are critical for prevention and treatment of malnutrition among children in rural areas. Hence, in this study, a community-based cross-sectional survey was conducted to clarify the status and associated factors of malnutrition among children under 6 years of age in rural Hunan Province. Some targeted interventions were proposed to improve the nutrition status of rural children. 


\section{Materials And Methods}

\section{Subjects}

The subjects were children under 6 years of age (0 to 71 months) and their caregivers from rural Hunan Province investigated between August and November 2019. The sample size was determined according to relevant equations for cross-sectional studies[19]. Since the stunting prevalence among rural children was estimated to be $16 \%[20]$, the size of a test a was 0.05 , permissible error $d$ was 0.10 , the designed effect of complex samples was 2 and the non-response rate was $20 \%$, and the final sample size was determined to be $5040(=2100 \times 2 \times 1.2)$.

Subjects were selected by multistage stratified cluster sampling. One province of China consists of several cities, and one city consists of several districts and several counties (districts and counties are urban and rural respectively). One county contains several towns, and one town has several villages[18]. The 14 cities in Hunan were divided by the economic condition into three levels: high, moderate and low. Then 2 cities from each economic level, 2 counties from each selected city, 2 towns from each selected county, and 3 villages from each tested town were randomly selected. From each village, all eligible children and their caregivers were included into our subjects. Totally, 5529 children from 72 villages covering 24 towns in 12 counties were involved.

\section{Data collection}

This study consisted of a questionnaire survey and anthropometric measurements. The questionnaire included children's factors (gender, age, birth weight, preterm birth, left-behind children, only child, passive smoking, regular physical examination), maternal gestational factors (age at delivery, gestational gain weight, moderate/severe anemia, pregnancy comorbidity), caregivers and family factors (type of caregivers, ethnicity, education level, occupation, family size, family income, family food expenditure). All children received anthropometric measurements, including length/height, and weight.

\section{Definition of variables}

The birth weight $<2500 \mathrm{~g}, 2500-3999 \mathrm{~g}$, and $\geq 4000 \mathrm{~g}$ were considered as low birth weight, normal birth weight, and macrosomia, respectively. Birth at $<37$ gestational weeks was regarded as premature birth. Left-behind children referred to those children whose parents (both or either) worked in other places and did not live together with them [18]. Only child was the only child born by one couple, and has no siblings. Passive smoking meant a nonsmoker inhaled at least 15 minutes every day the smoke exhaled by smokers for at least 1 day within 1 week. Maternal gestational weight gain was determined by the final weight of the mother measured at late pregnancy before delivery subtracted by the weight at early pregnancy[21] and was divided into four groups of $<10,10-14.99,15-19.99$, and $\geq 20 \mathrm{~kg}$. Maternal moderate/severe anemia was defined as a hemoglobin level $<100 \mathrm{~g} / \mathrm{L}[22]$. The maternal hemoglobin concentration in this study was the concentration in the third trimester of pregnancy, which was obtained based on the participants' recall for their hemoglobin detection during pregnancy. The maternal 
pregnancy comorbidities included gestational diabetes mellitus, gestational hypertension, pregnancy associated with cardiac diseases, gestational liver diseases, and thyroid dysfunction. Caregivers were those who took care of the diets, living and personal security for children and were divided into two types: parents, and grandparents/others. Ethnicity of caregivers was divided into Han and minorities. The education level of caregivers was classified into primary school or below, junior high school, senior high school, college or above. The occupation of caregivers was divided into housework, government agencies staff, business service staff, farmer, others. Family size was defined as the total number of family members and involved the members with economic relations and joint budget and diets, and was separated into $\leq 4,5-6$, and $\geq 7$.

\section{Anthropometric measurements}

The investigators used unified instruments to measure the length/heights and weights of children according to standardized methods, which were described by the Technical Specification for Children Health Check Service (China Ministry of Health, 2012). The lengths and weights of children aged 0-23 months were measured by using an FSG-25-YE lying-form infants and young children precision medical examination meter (Shanghai Betterren Medical Tech Co., Ltd.). The heights and weights of children aged 24-71 months were measured using an HX-200 stadiometer and an HCS-50-RT electronic scale respectively (Liheng Instrumentation LTD., Shanghai, China). The accuracies of instruments for length/heights and weights were $0.1 \mathrm{~cm}$ and $0.05 \mathrm{~kg}$, respectively.

\section{Evaluation criteria for children physical development}

The commonly-used indices for children physical development are length/height for age, weight for age, weight for length/height, and body mass index (BMI) for age. BMI was calculated using the ratio between children's weight in kilograms and length/height in meters squared $\left(\mathrm{kg} / \mathrm{m}^{2}\right)$ : BMI = weight $(\mathrm{kg}) / \mathrm{height}^{2}$ $\left(\mathrm{m}^{2}\right)$. The children physical development was evaluated using Z-score recommended by WHO: $\mathrm{Z}$ score = (analyzed index - median of reference standard)/standard deviation of reference standard. The WHO Child Growth Standards involve two age groups: 0-5 years (0-60 months) and 5-19 years (61-228 months), which are 2006 Child Growth Standard[23] and 2007 Child Growth Standard[24]. Hence, the physical development of children was evaluated according to the two age groups above.

- Children aged 0-60 months: length/height for age $z$ score (HAZ), weight for age $z$ score (WAZ) and weight for length/height $z$ score (WHZ) were calculated according to WHO 2006 Child Growth Standard. HAZ $<-2$ was defined as stunting, WAZ $<-2$ was defined as underweight, and $W H Z<-2$ was defined as wasting.

- Children aged 61-71 months: HAZ, WAZ, and BMI for age $z$ score (BMIZ) were calculated according to WHO 2007 Child Growth Standard. HAZ <-2 was defined as stunting, WAZ <-2 was defined as underweight, and $\mathrm{BMIZ}<-2$ was defined as wasting.

\section{Quality control}


The investigators were the child health care doctors selected from the county-level maternal and child health care hospitals of the corresponding counties. Prior to the survey, all the investigators were trained unifiedly, and only the qualified ones were allowed to take part in on-site survey. The instruments were calibrated before and during investigations. The physique measuring staff measured the length/height and weight of children in strict accordance with the specifications of the instruments. During the survey, all copies of the questionnaire were checked by quality control personnel: each copy should be filled in in a complete and standard way. Any illogical or missed response should be corrected in time. Data were double-inputted on Epidata 3.1 and tested in terms of consistency. For any inconsistent data, the original copy should be checked to ensure the high quality of any inputted data.

\section{Statistical analysis}

HAZ, WAZ, WHZ and BMIZ were computed using WHO anthropometric macros in SPSS (igrowup_SPSS and WHO2007_SPSS) [25,26], and statistical analyses were conducted on SPSS 25.0 (IBM, Chicago, IL, USA). The statistical description of categorical data was used proportion or rate. The stunting, underweight and wasting prevalence of children with different characteristics were compared by chisquare test. The significant variables identified from univariate analyses were involved into multivariate logistic regression analyses of stunting, underweight, and wasting. The independent variables were selected according to stepwise regression (forward: LR). All statistical tests were two-tailed, and the significant level was $P<0.05$.

\section{Ethics approval and consent to participate}

The study protocol was approved by the Ethics Committee of Hunan Provincial Maternal and Child Health Care Hospital (No.2019-S036). The study was conducted in accordance with the Declaration of Helsinki. Written informed consents were obtained from all the caregivers of children involved in this study.

\section{Results}

\section{Characteristics of children}

Totally 5800 copies of the questionnaire were sent out, and 5645 copies were returned, with a reply rate of $97.3 \%$. Of them, 5529 copies were valid, with a valid rate of $97.9 \%$. As shown in Table 1, of the 5529 children investigated, $50.8 \%$ were boys and $49.2 \%$ were girls. The major age groups were $48-59$ and $60-$ 71 months old, which accounted for $20.8 \%$ and $20.1 \%$ respectively. The proportions of low birth weight, and preterm birth were $3.7 \%$ and $4.8 \%$ respectively. The proportions of left-behind children and only child were $42.4 \%$ and $24.7 \%$ respectively. The proportions of children with passive smoking and regular physical examination were $43.8 \%$ and $88.5 \%$ respectively.

\section{Gestational conditions of mothers}

As shown in Table 2, the maternal age at delivery was mainly 25-29 years and 30-34 years, accounting for $30.8 \%$ and $40.8 \%$ respectively. The proportions of maternal gestational weight gain $<10 \mathrm{~kg}$, 
moderate/severe anemia, and pregnancy comorbidity were $19.1 \%, 4.9 \%$ and $9.9 \%$ respectively.

\section{Characteristics of caregivers and family}

As shown in Table 3, the caregivers were mostly parents (67.1\%). The ethnicity of caregivers was mostly Han (90.5\%), the education level was mainly junior middle school (38.4\%), and the dominant occupation was housework (57.4\%). The family size was mostly 5-6 members (53.6\%), the family annual income was mainly $\geq 60000$ (61.6\%), and the family annual food expenditure was mostly $\geq 6000$ Yuan (72.9\%).

\section{Prevalence of stunting, underweight, and wasting among children}

The prevalence of stunting, underweight, and wasting among the children were $4.4 \%$ (241/5529), 3.9\% $(217 / 5529)$, and $4.0 \%(221 / 5529)$ respectively. Univariate analyses showed that stunting was associated with 6 factors, including birth weight, preterm birth, maternal gestational weight gain, ethnicity of caregivers, education level of caregivers, and family food expenditure. Underweight was associated with 7 factors, including birth weight, preterm birth, maternal gestational weight gain, ethnicity of caregivers, education level of caregivers, family income, and family food expenditure. Wasting was associated with 7 factors, including birth weight, preterm birth, regular physical examination, ethnicity of caregivers, education level of caregivers, family size, and family food expenditure (Table 4).

\section{Associated factors of stunting, underweight, and wasting among children}

Multivariate logistic regression analyses showed that low birth weight $(<2500 \mathrm{~g})$ and maternal gestational weight gain $<10 \mathrm{~kg}$ were significantly associated with an increased risk of stunting in the children, with adjusted odds ratios (AORs) of 3.44 (95\% Cl: $2.23-5.31)$ and 1.74 (95\% Cl: 1.04-2.90) respectively. High education level of caregivers and high family food expenditure were protective factors of stunting in the children, with AORs of $0.80(95 \% \mathrm{Cl}$ : $0.69-0.92)$ and $0.85(95 \% \mathrm{Cl}$ : $0.73-0.99)$ respectively. Low birth weight $(<2500 \mathrm{~g})$, maternal gestational weight gain $<10 \mathrm{~kg}$ and ethnicity of caregivers being minority were significantly associated with an increased risk of underweight in the children, with AORs of 2.95 (95\% Cl: 1.73-5.03), 1.78 (95\%Cl: 1.01-3.19) and 1.99 (95\% Cl: 1.37-2.88) respectively. High education level of caregivers and high family food expenditure were protective factor of underweight in the children, with AORs of 0.82 (95\% Cl: $0.71-0.94)$ and 0.86 (95\% Cl: $0.74-0.98)$ respectively. Low birth weight ( $<2500 \mathrm{~g})$ and ethnicity of caregivers being minority were significantly associated with an increased risk of wasting in the children, with AORs of 2.27 (95\% Cl: 1.27-4.06) and 3.39 (95\% Cl: 2.46-4.68) respectively. High education level of caregivers was a protective factor of wasting in the children, with AOR of $0.79(95 \% \mathrm{Cl}$ : 0.69-0.91) (Table 5).

\section{Discussion}

\section{Malnutrition status of children}

The finding of this study showed that the prevalence of stunting, underweight and wasting among children under 6 years of age in rural Hunan are $4.4 \%, 3.9 \%$ and $4.0 \%$ respectively, which were lower 
compared with the majority of developing countries, especially Southeast Asia (e.g. Pakistan, Bhutan, Myanmar, India), and were close to those of developed countries, such as the USA[1, 7, 12, 27, 28]. A national family health investigation in India during 2015-2016 showed that the prevalence of stunting and underweight among children under 5 years of age were up to $38 \%$ and $35 \%$ respectively[28]. Compared with the 2010 epidemiological investigation in China, the nutritional status of children from poor rural areas was significantly improved and the prevalence of stunting and underweight decline from $20.3 \%$ to $4.4 \%$, and from $8.0 \%$ to $3.9 \%$ respectively[5]. The prevalence of stunting and underweight among children under 6 years of age in rural Hunan has met the requirements by China Child Development Outline (2011-2020) (be lower than 7\% and 5\% respectively).

The significant improvement in the nutritional status of children in poor rural areas was attributed to a variety of factors, including family income increment, dietary structure optimization, improved health conditions, improved maternal education level, and extensive implementation of nutrition improvement projects, etc $[5,8,14]$. As one of the few provinces to first implement the national child nutrition improvement projects in poverty-stricken regions of China, the project in 2012 covered 20 counties of Hunan, expanded to 25 counties in 2014, and adjusted to 53 counties in 2018, which covered all povertystricken villages of Hunan. Specifically, all children aged 6-23 months in poverty-stricken areas were provided for free with $1 \mathrm{bag} /$ day of supplementary nutrition foods (Yingyangbao, YYB for short) containing 6 vitamins and 3 minerals ( $\mathrm{Ca}, \mathrm{Fe}, \mathrm{Zn})[14]$. Also childhood nutrition knowledge was propagandized to the caregivers. A meta-analysis in China showed that this project could remarkably improve the nutritional status of children, and persistent intake of Yingyangbao would reduce the risks of anemia, stunting, and underweight among children by $45 \%, 40 \%$ and $49 \%$ respectively[29].

\section{Associated factors of malnutrition in children}

\section{Birth weight}

Birth weight is a key indicator about the intrauterine nutrition status of the fetus, and is one of the critical factors that decide postnatal growth and development. A cross-sectional study in Iran demonstrated that the physical development levels (e.g. length, weight, head circumference) of infants with low or extremely low birth weight were significantly lower at the 18-th month compared with infants with normal birth weight [30]. Several observational studies confirmed that low birth weight was an independent risk factor of malnutrition in children $[12,31,32]$. The present study found that low birth weight was the most important influence factor on the malnutrition of children in rural Hunan, and the risks of children with low birth weight to suffer stunting, underweight and wasting were 3.44, 2.95 and 2.27 times of children with normal birth weight, respectively. Infants with low birth weight are more common in preterm birth or intrauterine growth retardation, and the functions of their organs/systems are undeveloped, such as imperfect sucking and swallowing abilities, poor digestion and absorption, and difficulties in feeding. Moreover, these infants have low autoimmunity and are susceptible to the harmful external environment and diseases, which can lead to the delayed growth and development [33].

\section{Maternal gestational weight gain}


The gestational nutrition of the mother is closely related to the child's growth and development [12, 21 , 34]. A retrospective cohort study in China showed that the pre-pregnant BMI and gestational weight gain of the mother were both positively correlated with the WAZ and HAZ of children aged 12 months[34]. Data analysis of a National Demographic and Health Survey in Myanmar during 2015-2016 showed that maternal nutritional inadequacy would raise the risks of underweight and wasting among children under 5 years of age[12]. Similarly, our study demonstrated that maternal gestational weight gain was related to the malnutrition of children, and weight gain $<10 \mathrm{~kg}$ would increase the risks of stunting and underweight of children by $74 \%$ and $78 \%$ respectively, but we found no association between maternal gestational weight gain and wasting of children. Though studies have shown that the increase of maternal gestational weight gain will reduce the risk of malnutrition in children [21], it does not mean the larger weight gain is better, which is because excessive gestational weight gain will in turn increase the risk of overweight/obesity in children $[35,36]$. Hence, providing mothers with regular prenatal care and reasonable diet to avoid gestational excessive or insufficient weight gain are significant for the prevention of malnutrition in children.

\section{Ethnicity of caregivers}

Hunan is a multiracial province in Central South China and is dwelt by $9.5 \%$ of minorities, including Miao, Tujia, and Dong, etc. Though previous studies showed the ethnicity of the mother or caregivers was related to the malnutrition of children, the findings were inconsistent $[15,18]$. Zhou et al. found that the ethnicity of Miao or Tujia was a protective factor of malnutrition in children, as the prevalence of malnutrition in Miao and Tujia children were lower than that of Han children[15]. A cross-sectional study in rural poor areas of China suggested that ethnicity of Tibetan, Yi or other minorities were risk factors of stunting in children, as the risks of stunting were 2.35, 1.95 and 1.42 times higher compared with Han children[18]. Our findings were different from the above two studies and indicated that ethnicity of minority was a risk factor of underweight and wasting in children, but was not related to stunting. The differences might be attributed to two reasons. Firstly, the economy, cultures, religions, living conditions and life customs were all different among ethnics. Secondly, the sample sizes, definitions of indices, and data analyses were all different among studies, as Zhou et al. concerned the total prevalence of malnutrition, but ignored the types of malnutrition.

\section{Education levels and family incomes}

Many observational studies have confirmed that high education level of mothers or caregivers and high family income were two protective factors against malnutrition of children[8, 27, 31, 32, 37, 38]. Our study showed that as the education level of caregivers and the family food expenditure increase, the risk of malnutrition in children was lowered, which was consistent with other studies. This was because the increased education level of caregivers could largely improve their acceptance of nutrition and health knowledge, which thereby promoted the scientific feeding and diet balancing of children [5]. Generally, family food expenditure will not increase unless the family incomes rise, and thus is the most direct and objective reflection of family incomes. Since family incomes and family food expenditure are collinear, 
the variable of family income was not involved in the multivariate logistic regression models. Nevertheless, the protective effect of family food expenditure on malnutrition among children directly reflects the protective effect of family incomes on malnutrition.

\section{Limitations}

This cross-sectional study has some limitations. First, the relationship between tested factors and malnutrition is statistics, rather than causality. Second, data about the gestational weight gain of mothers and the birth weights of children were both acquired from the recalling of caregivers, which inevitably resulted in memory bias. Third, some important factors were ignored, such as dietary patterns, diseases (e.g. recurrent respiratory infection, diarrhea) and genetic factors (e.g. heights and body sizes of parents). Nonetheless, this large-size epidemiological study involves 5529 children from 72 villages across 24 towns in 12 counties of Hunan, and covers the whole preschool age group. Hence, our findings reflect the malnutrition statuses and associated factors of children (age $<6$ years) in rural Hunan and will help health administrations to lower the malnutrition-caused burdens in rural areas.

\section{Conclusions}

The nutrition status of rural children under age of 6 years from Hunan is significantly improved, and the prevalence of stunting, underweight and wasting is very low. Malnutrition of children in this region is affected by birth weight, maternal gestational weight gain, ethnicity of caregivers, education level of caregivers, and family food expenditure. Attention must be focused on strengthening the gestational care and reasonable diet of mothers, and on avoiding nutritional deficiency during pregnancy, which will reduce the occurrence of low birth weight. Moreover, education about nutrition should be strengthened among minorities.

\section{Abbreviations}

WHO: World Health Organization; HAZ: Length/height for Age Z Score; WAZ: Weight for Age Z Score; WHZ: Weight for Length/height Z Score; BMIZ: Body Mass Index for Age Z Score; AOR: Adjusted Odds Ratio; Cl: Confidence Interval.

\section{Declarations}

\section{Ethics approval and consent to participate}

The study protocol was approved by the Ethics Committee of Hunan Provincial Maternal and Child Health Care Hospital (No.2019-S036). The study was conducted in accordance with the Declaration of Helsinki. Written informed consents were obtained from all the caregivers of children involved in this study.

\section{Consent for publication}


Not applicable

\section{Availability of data and material}

The datasets generated during and/or analysed during the current study are not publicly available duo to the personal privacy of subjects but are available from the corresponding author on reasonable request.

\section{Competing interests}

The authors declared that they have no competing interest.

\section{Funding}

This study was supported by the Hunan Provincial Health Commission (No.20201924) and Hunan Provincial Science and Technology Department (No.2019SK1015).

\section{Authors' contributions}

HXL, GWH and HW conceived the research idea. HXL participated in the data collection, statistical analysis and preparation of the manuscript. SY and AWH performed the data collection and statistical analysis. SY, HLF and QH performed the data collection. GWH and HW provided the critical review of the manuscript. All authors read and approved the final manuscript.

\section{Acknowledgements}

We would like to thank all the researchers from local county-level maternal and child health care hospital as well as to all caregivers of children who participated in this study from the 12 counties in Hunan Province.

\section{References}

1. Khan S, Zaheer S, Safdar NF. Determinants of stunting, underweight and wasting among children $<5$ years of age: evidence from 2012-2013 Pakistan Demographic and Health Survey. BMC Public Health. 2019; 19(1):358.

2. Kang Y, Aguayo VM, Campbell RK, West KP Jr. Association between stunting and early childhood development among children aged 36-59 months in South Asia. Matern Child Nutr. 2018; Suppl 4:e12684.

3. Olsen MF, luel-Brockdorff AS, Yaméogo CW, Cichon B, Fabiansen C, Filteau S, et al. Early development in children with moderate acute malnutrition: a cross-sectional study in Burkina Faso. Matern Child Nutr. 2019:e12928.

4. Emerson E, Savage A, Llewellyn G. Prevalence of underweight, wasting and stunting among young children with a significant cognitive delay in 47 low-income and middle-income countries. J Intellect Disabil Res. 2020; 64(2):93-102. 
5. Ministry of Health. The nutrition development report of Chinese children aged 0-6 (2012). Beijing: Ministry of Health; 2012. (In Chinese).

6. World Health Organization. Child malnutrition.https://www.who.int/data/gho/data/themes/theme details/GHO/child-malnutrition. Accessed 15 Dec 2019.

7. Akombi BJ, Chitekwe S, Sahle BW, Renzaho AMN. Estimating the double burden of malnutrition among 595,975 children in 65 low- and middle-income countries: a meta-analysis of demographic and health surveys. Int J Environ Res Public Health. 2019; 16(16). pii: E2886.

8. Wu L, Yang Z, Yin SA, Zhu M, Gao H. The relationship between socioeconomic development and malnutrition in children younger than 5 years in China during the period 1990 to 2010. Asia Pac J Clin Nutr. 2015; 24(4):665-73.

9. Tanaka J, Yoshizawa K, Hirayama K, Karama M, Wanjihia V, Changoma MS, et al. Relationship between dietary patterns and stunting in preschool children: a cohort analysis from Kwale, Kenya. Public Health. 2019; 173:58-68.

10. Tekile AK, Woya AA, Basha GW. Prevalence of malnutrition and associated factors among under-five children in Ethiopia: evidence from the 2016 Ethiopia Demographic and Health Survey. BMC Res Notes. 2019; 12(1):391.

11. Ansuya, Nayak BS, Unnikrishnan B, George A, N SY, Mundkur SC, et al. Risk factors for malnutrition among preschool children in rural Karnataka: a case-control study. BMC Public Health. 2018; 18(1):283.

12. Khaing HT, Nomura S, Yoneoka D, Ueda P, Shibuya K. Risk factors and regional variations of malnutrition among children under 5 in Myanmar: cross-sectional analyses at national and subnational levels. BMJ Open. 2019; 9(9):e030894.

13. Hintsa S, Gereziher K. Determinants of underweight among 6-59 months old children in Berahle, Afar, North East Ethiopia: a case control study 2016. BMC Res Notes. 2019; 12(1):753.

14. Huo J. Ying Yang Bao: improving complementary feeding for Chinese infants in poor regions. Nestle Nutr Inst Workshop Ser. 2017; 87:131-8.

15. Zhou X, Fang JQ, Luo JY, Wang H, Du QY, Huang GW, et al. Factors associated with malnutrition among infants and young children aged 6-23 months in poor rural areas in Hunan Province, China. Zhonghua Yu Fang Yi Xue Za Zhi. 2017; 51(8):751-5. (In Chinese).

16. Ban L, Guo S, Scherpbier RW, Wang X, Zhou H, Tata LJ. Child feeding and stunting prevalence in leftbehind children: a descriptive analysis of data from a central and western Chinese population. Int $\mathrm{J}$ Public Health. 2017; 62(1):143-51.

17. Wang J, Wang H, Chang S, Zhao L, Fu P, Yu W, et al. The influence of malnutrition and micronutrient status on anemic risk in children under 3 years old in poor areas in China. PLoS One. 2015; 10(10):e0140840.

18. Zhang $Y$, Huang $X$, Yang $Y$, Liu X, Yang $C$, Wang A, et al. Double burden of malnutrition among children under 5 in poor areas of China. PLoS One. 2018; 13(9):e0204142.

19. Li LM. Epidemiology. 6th ed. Beijing: People's Medical Publishing House; 2008. (In Chinese). 
20. Zeng R, Mou JS, Luo JY, Du QY, Wu H, Zhang L, et al. Prevalence and risk factors for malnutrition among 15142 children aged 0-7 in rural areas. Wei Sheng Yan Jiu. 2009; 38:624-7. (In Chinese).

21. Li C, Zhu N, Zeng L, Dang S, Zhou J, Pei L, et al. Effect of maternal pre-pregnancy underweight and average gestational weight gain on physical growth and intellectual development of early schoolaged children. Sci Rep. 2018; 8(1):12014.

22. World Health Organization. Haemoglobin concentrations for the diagnosis of anaemia and assessment of severity. Vitamin and Mineral Nutrition Information System. Geneva: World Health Organization.; 2011. https://www.who.int/vmnis/ indicators/haemoglobin.pdf. Accessed 29 Mar 2015.

23. WHO Multicentre Growth Reference Study Group. WHO child growth standards: length/height-for-age, weight-for-age, weight-for length, weight-for-height and body mass index-for-age: methods and development. Geneva: WHO; 2006.

24. de Onis M, Onyango AW, Borghi E, Siyam A, Nishida C, Siekmann J. Development of a WHO growth reference for school-aged children and adolescents. Bull World Health Organ. 2007; 85(9):660-7.

25. World Health Organization. WHO anthro survey analyser and other tools. https://www.who.int/ childgrowth/software/en/. Accessed 6 Jul 2016.

26. World Health Organization. Growth reference 5-19 years: application tools. https://www.who.int/ growthref/tools/en/. Accessed 6 Jul 2016.

27. Kang Y, Aguayo VM, Campbell RK, Dzed L, Joshi V, Waid JL, et al. Nutritional status and risk factors for stunting in preschool children in Bhutan. Matern Child Nutr. 2018; Suppl 4:e12653.

28. Singh S, Srivastava S, Upadhyay AK. Socio-economic inequality in malnutrition among children in India: an analysis of 640 districts from National Family Health Survey (2015-16). Int J Equity Health. 2019; 18(1):203.

29. Li Z, Li X, Sudfeld CR, Liu Y, Tang K, Huang Y, et al. The effect of the yingyangbao complementary food supplement on the nutritional status of infants and children: a systematic review and metaanalysis. Nutrients. 2019; 11(10). pii: E2404.

30. Abdeyazdan Z, Ehsanpour S, Hemmati E. Evaluation of growth and development pattern in normal, low and very low birth weight neonatesat 18 months of age. J Educ Health Promot. 2014; 3:102.

31. Nshimyiryo A, Hedt-Gauthier B, Mutaganzwa C, Kirk CM, Beck K, Ndayisaba A, et al. Risk factors for stunting among children under five years: a cross-sectional population-based study in Rwanda using the 2015 Demographic and Health Survey. BMC Public Health. 2019; 19(1):175.

32. Berhe K, Seid O, Gebremariam Y, Berhe A, Etsay N. Risk factors of stunting (chronic undernutrition) of children aged 6 to 24 months in Mekelle City, Tigray Region, North Ethiopia: an unmatched casecontrol study. PLoS One. 2019; 14(6):e0217736.

33. Li HX, Zheng JF, Huang GW, Xiao J, Wang AH, Feng N, et al. Effects of birth weight on growth and development and anemia among 6-23 months old infants in rural Hunan. Chin J Public Health. 2019; 35(6):726-30. (In Chinese). 
34. Zhang W, Niu F, Ren X. Association of maternal pre-pregnancy body mass index and gestational weight gain with Chinese infant growth. J Paediatr Child Health. 2019; 55(6):673-9.

35. Liang JJ, Hu Y, Xing YF, Ma Y, Jiang L, Liu HY, et al. Association between both maternal prepregnancy body mass index/gestational weight gain and overweight/obesity children at preschool stag. Zhonghua Liu Xing Bing Xue Za Zhi. 2019; 40(8):976-81. (In Chinese).

36. Josey MJ, McCullough LE, Hoyo C, Williams-DeVane C. Overall gestational weight gain mediates the relationship between maternal and child obesity. BMC Public Health. 2019; 19(1):1062.

37. Jiang $Y$, Su $X$, Wang $C$, Zhang $L$, Zhang $X$, Wang $L$, et al. Prevalence and risk factors for stunting and severe stunting among children under three years old in mid-western rural areas of China. Child Care Health Dev. 2015; 41(1):45-51.

38. Hein AK, Hong SA, Puckpinyo A, Tejativaddhana P. Dietary diversity, social support and stunting among children aged 6-59 months in an internally displaced persons camp in Kayin State, Myanmar. Clin Nutr Res. 2019; 8(4):307-17.

\section{Tables}

Table 1 Characteristics of children under 6 years old who participated in the study 


\begin{tabular}{|c|c|c|}
\hline Characteristics & Frequency (n) & Percentage (\%) \\
\hline \multicolumn{3}{|l|}{ Sex of children } \\
\hline Female & 2723 & 49.2 \\
\hline Male & 2806 & 50.8 \\
\hline \multicolumn{3}{|c|}{ Age of children (months) } \\
\hline $0-11$ & 716 & 12.9 \\
\hline $12-23$ & 800 & 14.5 \\
\hline $24-35$ & 835 & 15.1 \\
\hline $36-47$ & 914 & 16.5 \\
\hline $48-59$ & 1150 & 20.8 \\
\hline $60-71$ & 1114 & 20.1 \\
\hline \multicolumn{3}{|l|}{ Birth weight } \\
\hline$<2500 \mathrm{~g}$ & 203 & 3.7 \\
\hline $2500-3999 \mathrm{~g}$ & 4968 & 89.9 \\
\hline$\geq 4000 \mathrm{~g}$ & 358 & 6.5 \\
\hline \multicolumn{3}{|l|}{ Preterm birth } \\
\hline No & 5264 & 95.2 \\
\hline Yes & 265 & 4.8 \\
\hline \multicolumn{3}{|c|}{ Left behind children } \\
\hline No & 3184 & 57.6 \\
\hline Yes & 2345 & 42.4 \\
\hline \multicolumn{3}{|l|}{ Only child } \\
\hline No & 4157 & 75.2 \\
\hline Yes & 1372 & 24.8 \\
\hline \multicolumn{3}{|c|}{ Passive smoking } \\
\hline No & 3110 & 56.2 \\
\hline Yes & 2419 & 43.8 \\
\hline \multicolumn{3}{|c|}{ Regular physical examination } \\
\hline No & 634 & 11.5 \\
\hline
\end{tabular}


Table 2 Characteristics of children's mothers during pregnancy

\begin{tabular}{|lll|}
\hline Characteristics & Frequency $(\mathrm{n})$ & Percentage (\%) \\
\hline Maternal age at delivery (years) & & \\
\hline$<20$ & 25 & 0.5 \\
\hline $20-24$ & 394 & 7.1 \\
\hline $25-29$ & 1702 & 30.8 \\
\hline $30-34$ & 2258 & 40.8 \\
\hline $35-39$ & 806 & 14.6 \\
\hline$\geq 40$ & 344 & 6.2 \\
\hline Maternal gestational weight gain (kg) & & 2 \\
\hline$<10$ & 1058 & 19.1 \\
\hline $10-14.99$ & 2356 & 42.6 \\
\hline $15-19.99$ & 1402 & 25.4 \\
\hline$\geq 20$ & 713 & 12.9 \\
\hline Maternal moderate/severe anemia & & \\
\hline No & 5258 & 95.1 \\
\hline Yes & 271 & 4.9 \\
\hline Pregnancy comorbidity & & 9.9 \\
\hline No & 4982 & \\
\hline Yes & 547 & \\
\hline
\end{tabular}

Table 3 Characteristics of caregivers and family 


\begin{tabular}{|c|c|c|}
\hline Characteristics & Frequency (n) & Percentage (\%) \\
\hline \multicolumn{3}{|l|}{ Type of caregivers } \\
\hline Parents & 3711 & 67.1 \\
\hline Grandparents/other & 1818 & 32.9 \\
\hline \multicolumn{3}{|l|}{ Ethnicity of caregivers } \\
\hline Han & 5005 & 90.5 \\
\hline Minorities & 524 & 9.5 \\
\hline \multicolumn{3}{|l|}{ Education level of caregivers } \\
\hline Primary school or below & 1116 & 20.2 \\
\hline Junior high school & 2121 & 38.4 \\
\hline Senior high school & 1248 & 22.6 \\
\hline College or above & 1044 & 18.9 \\
\hline \multicolumn{3}{|l|}{ Occupation of caregivers } \\
\hline Housework & 3175 & 57.4 \\
\hline Government agencies staff & 673 & 12.2 \\
\hline Business services staff & 457 & 8.3 \\
\hline Farmer & 355 & 6.4 \\
\hline Other & 869 & 15.7 \\
\hline \multicolumn{3}{|l|}{ Family size } \\
\hline$\leq 4$ & 1644 & 29.7 \\
\hline $5-6$ & 2963 & 53.6 \\
\hline$\geq 7$ & 922 & 16.7 \\
\hline \multicolumn{3}{|l|}{ Family income (Yuan/year) } \\
\hline$<20000$ & 237 & 4.3 \\
\hline 20000-39999 & 612 & 11.1 \\
\hline $40000-59999$ & 1275 & 23.1 \\
\hline$\geq 60000$ & 3405 & 61.6 \\
\hline \multicolumn{3}{|c|}{ Family food expenditure (Yuan/year) } \\
\hline$<2000$ & 127 & 2.3 \\
\hline
\end{tabular}




\begin{tabular}{|lll|}
\hline $2000-3999$ & 585 & 10.6 \\
\hline $4000-5999$ & 789 & 14.3 \\
& & \\
\hline 6000 & 4028 & 72.9 \\
\hline
\end{tabular}

Table 4 The prevalence of malnutrition according to children, mothers, caregivers and family characteristics 


\begin{tabular}{|c|c|c|c|c|c|c|c|}
\hline \multirow[t]{2}{*}{ Characteristics } & \multirow[t]{2}{*}{ Frequency } & \multicolumn{6}{|c|}{ Protein-energy malnutrition, $\mathrm{n}(\%)$} \\
\hline & & Stunting & $P^{a}$ & Underweight & $P^{b}$ & Wasting & $P^{c}$ \\
\hline \multicolumn{8}{|l|}{ Children levels } \\
\hline Sex of children & & & 0.053 & & 0.341 & & 0.983 \\
\hline Female & 2723 & 104(3.8) & & $100(3.7)$ & & $109(4.0)$ & \\
\hline Male & 2806 & $137(4.9)$ & & $117(4.2)$ & & $112(4.0)$ & \\
\hline $\begin{array}{l}\text { Age of children } \\
\text { (months) }\end{array}$ & & & 0.236 & & 0.599 & & 0.057 \\
\hline $0-11$ & 716 & $22(3.1)$ & & $21(2.9)$ & & $17(2.4)$ & \\
\hline $12-23$ & 800 & $43(5.4)$ & & $31(3.9)$ & & $24(3.0)$ & \\
\hline $24-35$ & 835 & $36(4.3)$ & & $30(3.6)$ & & $33(4.0)$ & \\
\hline $36-47$ & 914 & $39(4.3)$ & & $35(3.8)$ & & $39(4.3)$ & \\
\hline $48-59$ & 1150 & $58(5.0)$ & & $52(4.5)$ & & $54(4.7)$ & \\
\hline $60-71$ & 1114 & $43(3.9)$ & & $48(4.3)$ & & $54(4.8)$ & \\
\hline Birth weight & & & 0.000 & & 0.000 & & 0.000 \\
\hline$<2500 \mathrm{~g}$ & 203 & $27(13.3)$ & & $27(13.3)$ & & $21(10.3)$ & \\
\hline $2500-3999 \mathrm{~g}$ & 4968 & $207(4.2)$ & & 187(3.8) & & 194(3.9) & \\
\hline$\geq 4000 \mathrm{~g}$ & 358 & $7(2.0)$ & & $3(0.8)$ & & $6(1.7)$ & \\
\hline Preterm birth & & & 0.000 & & 0.000 & & 0.000 \\
\hline No & 5264 & $216(4.1)$ & & 191(3.6) & & 199(3.8) & \\
\hline Yes & 265 & $25(9.4)$ & & $26(9.8)$ & & $22(8.3)$ & \\
\hline Left behind children & & & 0.768 & & 0.480 & & 0.553 \\
\hline No & 3184 & $141(4.4)$ & & $130(4.1)$ & & 123(3.9) & \\
\hline Yes & 2345 & $100(4.3)$ & & $87(3.7)$ & & $98(4.2)$ & \\
\hline Only child & & & 0.562 & & 0.437 & & 0.542 \\
\hline No & 4157 & $185(4.5)$ & & $168(4.0)$ & & $170(4.1)$ & \\
\hline Yes & 1372 & $56(4.1)$ & & $49(3.6)$ & & $51(3.7)$ & \\
\hline Passive smoking & & & 0.953 & & 0.333 & & 0.431 \\
\hline No & 3110 & $136(4.4)$ & & $129(4.1)$ & & $130(4.2)$ & \\
\hline
\end{tabular}




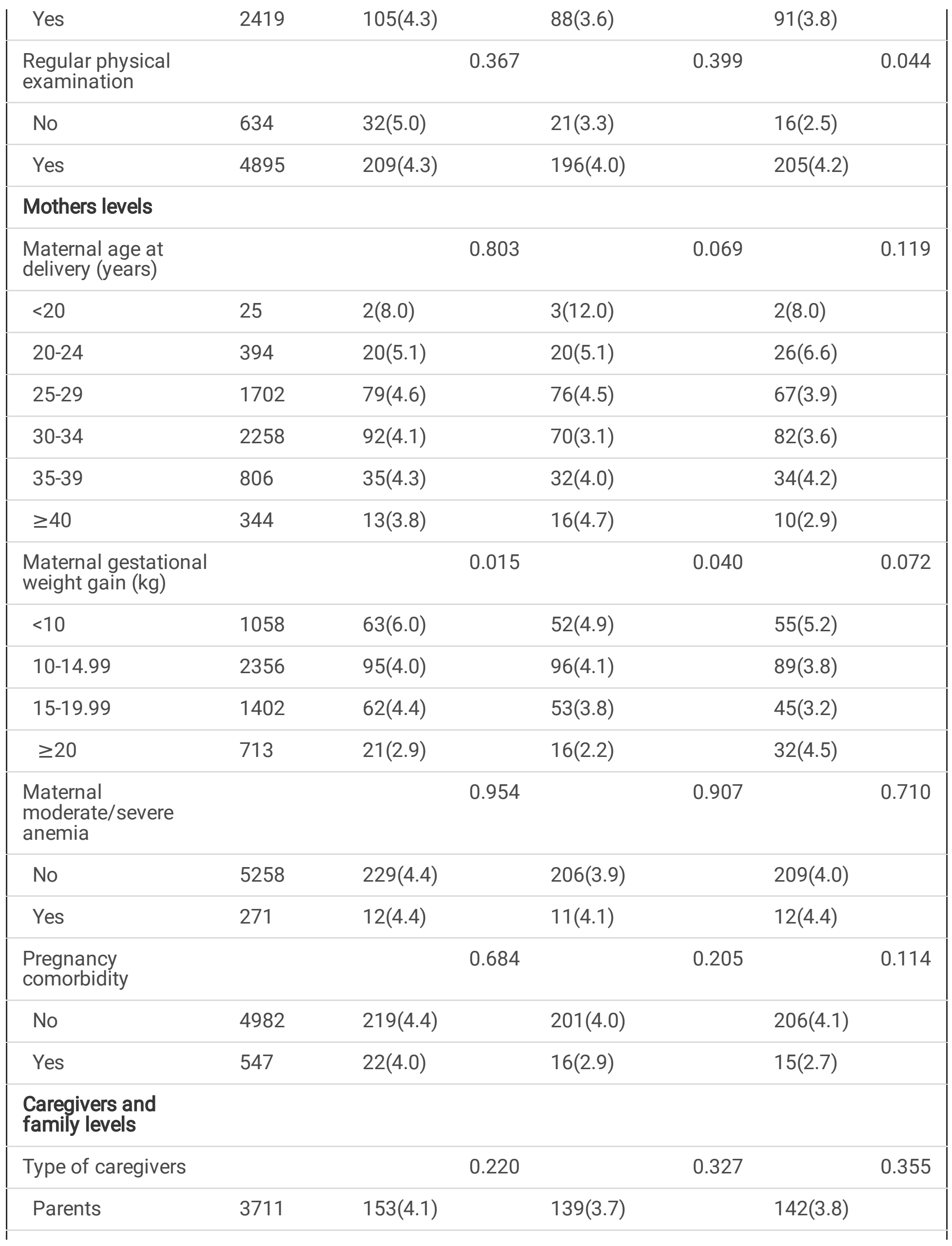




\begin{tabular}{|c|c|c|c|c|c|c|c|}
\hline Grandparents/other & 1818 & $88(4.8)$ & & $78(4.3)$ & & $79(4.3)$ & \\
\hline $\begin{array}{l}\text { Ethnicity of } \\
\text { caregivers }\end{array}$ & & & 0.003 & & 0.000 & & 0.000 \\
\hline Han & 5005 & $205(4.1)$ & & 177(3.5) & & 163(3.3) & \\
\hline Minorities & 524 & $36(6.9)$ & & $40(7.6)$ & & $58(11.1)$ & \\
\hline $\begin{array}{l}\text { Education level of } \\
\text { caregivers }\end{array}$ & & & 0.001 & & 0.003 & & 0.000 \\
\hline $\begin{array}{l}\text { Primary school or } \\
\text { below }\end{array}$ & 1116 & $63(5.6)$ & & $54(4.8)$ & & $64(5.7)$ & \\
\hline Junior high school & 2121 & $106(5.0)$ & & $96(4.5)$ & & $93(4.4)$ & \\
\hline Senior high school & 1248 & $46(3.7)$ & & $45(3.6)$ & & $36(2.9)$ & \\
\hline College or above & 1044 & $26(2.5)$ & & $22(2.1)$ & & $28(2.7)$ & \\
\hline $\begin{array}{l}\text { Occupation of } \\
\text { caregivers }\end{array}$ & & & 0.105 & & 0.795 & & 0.138 \\
\hline Housework & 3175 & $157(4.9)$ & & $129(4.1)$ & & 132(4.2) & \\
\hline $\begin{array}{c}\text { Government } \\
\text { agencies staff }\end{array}$ & 673 & $20(3.0)$ & & $23(3.4)$ & & $19(2.8)$ & \\
\hline $\begin{array}{l}\text { Business services } \\
\text { staff }\end{array}$ & 457 & $15(3.3)$ & & $16(3.5)$ & & $12(2.6)$ & \\
\hline Farmer & 355 & $16(4.5)$ & & $17(4.8)$ & & $15(4.2)$ & \\
\hline Other & 869 & $33(3.8)$ & & $32(3.7)$ & & $43(4.9)$ & \\
\hline Family size & & & 0.307 & & 0.054 & & 0.039 \\
\hline$\leq 4$ & 1644 & $62(3.8)$ & & $51(3.1)$ & & $56(3.4)$ & \\
\hline $5-6$ & 2963 & $133(4.5)$ & & $120(4.0)$ & & $115(3.9)$ & \\
\hline$\geq 7$ & 922 & $46(5.0)$ & & $46(5.0)$ & & $50(5.4)$ & \\
\hline $\begin{array}{l}\text { Family income ( } \\
\text { Yuan/year) }\end{array}$ & & & 0.080 & & 0.010 & & 0.094 \\
\hline$<20000$ & 237 & $14(5.9)$ & & $17(7.2)$ & & $15(6.3)$ & \\
\hline 20000-39999 & 612 & $35(5.7)$ & & $32(5.2)$ & & $27(4.4)$ & \\
\hline 40000-59999 & 1275 & $61(4.8)$ & & $50(3.9)$ & & $58(4.5)$ & \\
\hline$\geq 60000$ & 3405 & 131(3.8) & & 118(3.5) & & 121(3.6) & \\
\hline $\begin{array}{l}\text { Family food } \\
\text { expenditure } \\
\text { (Yuan/year) }\end{array}$ & & & 0.004 & & 0.008 & & 0.002 \\
\hline
\end{tabular}




\begin{tabular}{|lllll|}
\hline$<2000$ & 127 & $10(7.9)$ & $8(6.3)$ & $5(3.9)$ \\
\hline $2000-3999$ & 585 & $39(6.7)$ & $36(6.2)$ & $40(6.8)$ \\
\hline $4000-5999$ & 789 & $34(4.3)$ & $33(4.2)$ & $35(4.4)$ \\
& & & & \\
\hline Total & 4028 & $158(3.9)$ & $140(3.5)$ & $141(3.5)$ \\
\hline
\end{tabular}

a The comparison of stunting prevalence in children with different characteristics.

$\mathrm{b}$ The comparison of underweight prevalence in children with different characteristics.

${ }^{\mathrm{c}}$ The comparison of wasting prevalence in children with different characteristics.

Table 5 Factors associated with children malnutrition in multivariate analysis 


\begin{tabular}{|c|c|c|c|c|c|c|}
\hline \multirow[t]{2}{*}{ Factors } & \multicolumn{2}{|c|}{ Stunting } & \multicolumn{2}{|c|}{ Underweight } & \multicolumn{2}{|c|}{ Wasting } \\
\hline & AOR & $95 \% \mathrm{Cl}$ & AOR & $95 \% \mathrm{Cl}$ & AOR & $95 \% \mathrm{Cl}$ \\
\hline \multicolumn{7}{|l|}{ Birth weight } \\
\hline$<2500 \mathrm{~g}$ & 3.44 & $2.23-5.31$ & 2.95 & $\begin{array}{l}1.73- \\
5.03\end{array}$ & 2.27 & $\begin{array}{l}1.27- \\
4.06\end{array}$ \\
\hline $2500-3999 \mathrm{~g}$ & 1.00 & & 1.00 & & 1.00 & \\
\hline$\geq 4000 \mathrm{~g}$ & 0.48 & $0.22-1.03$ & 0.22 & $\begin{array}{l}0.07- \\
0.70\end{array}$ & 0.44 & $\begin{array}{l}0.19- \\
1.00\end{array}$ \\
\hline \multicolumn{7}{|l|}{$\begin{array}{l}\text { Maternal } \\
\text { gestational } \\
\text { weight gain } \\
(\mathrm{kg})\end{array}$} \\
\hline$<10$ & 1.74 & $1.04-2.90$ & 1.78 & $\begin{array}{l}1.01- \\
3.19\end{array}$ & & \\
\hline $10-14.99$ & 1.25 & $0.77-2.03$ & 1.64 & $\begin{array}{l}0.95- \\
2.83\end{array}$ & & \\
\hline $15-19.99$ & 1.48 & $0.89-2.45$ & 1.63 & $\begin{array}{l}0.92- \\
2.89\end{array}$ & & \\
\hline$\geq 20$ & 1.00 & & 1.00 & & & \\
\hline \multicolumn{7}{|l|}{$\begin{array}{l}\text { Ethnicity of } \\
\text { caregivers }\end{array}$} \\
\hline Han & 1.00 & & 1.00 & & 1.00 & \\
\hline Minorities & 1.42 & $\begin{array}{l}0.97- \\
2.07\end{array}$ & 1.99 & $\begin{array}{l}1.37- \\
2.88\end{array}$ & 3.39 & $\begin{array}{l}2.46- \\
4.68\end{array}$ \\
\hline $\begin{array}{l}\text { Education } \\
\text { level of } \\
\text { caregivers }\end{array}$ & 0.80 & $0.69-0.92$ & 0.82 & $\begin{array}{l}0.71- \\
0.94\end{array}$ & 0.79 & $\begin{array}{l}0.69 \\
-0.91\end{array}$ \\
\hline $\begin{array}{l}\text { Family food } \\
\text { expenditure } \\
\text { (Yuan/year) }\end{array}$ & 0.85 & 0.73-0.99 & 0.86 & $\begin{array}{l}0.74- \\
0.98\end{array}$ & & \\
\hline
\end{tabular}

$A O R=$ adjusted odds ratio; $\mathrm{Cl}=$ confidence interval. 